\title{
Lesão periférica de células gigantes em região palatina anterior: excisão cirúrgica e acompanhamento de um ano
}

\author{
Peripheral giant cell lesion in anterior palate: surgical excision \\ and one year follow up
}

\author{
Samuel Rocha França* \\ Maria Franciele Soares Matos ${ }^{* *}$ \\ Marcelo Bonifácio da Silva Sampieri ${ }^{* * *}$ \\ Filipe Nobre Chaves ${ }^{* * * *}$ \\ Karuza Maria Alves Pereira** \\ Ana Paula Negreiros Nunes Alves*
}

\section{Resumo}

A lesão periférica de células gigantes (LPCG) é considerada um processo proliferativo não neoplásico. Acredita-se que seu fator etiológico esteja associado ao fator reacional, como o trauma ou a irritação local. Tal lesão pode se desenvolver em região anterior e região posterior de gengiva ou em rebordo alveolar, sendo a mandíbula mais afetada do que a maxila. Objetivo: este estudo relata o caso clínico de uma paciente do sexo feminino, 38 anos de idade, que possuía um crescimento exofítico em região anterior de palato duro. Relato de caso: esse crescimento apresentava formato nodular, de superfície lobulada com áreas ulceradas, medindo $20 \mathrm{~mm}$, localizado na região de papila incisiva. Com base nas características clínicas, o tratamento realizado foi a biópsia excisional, seguido de raspagem e alisamento radicular. No exame histopatológico, foram evidenciadas áreas de proliferação de células gigantes e discreta pigmentação por hemossiderina, confirmando a hipótese diagnóstica de LPCG. Considerações finais: o acompanhamento pós-operatório evidenciou um ótimo processo de cicatrização sem recidiva após um ano desde o início do tratamento.

Palavras-chave: Biópsia. Lesão periférica de células gigantes. Placa dental.

\section{Introdução}

A lesão periférica de células gigantes (LPCG) é considerada um processo proliferativo não neoplásico. Acredita-se que esteja associada ao fator reacional, como o trauma ou a irritação local. Tal lesão pode se desenvolver em região anterior e região posterior de gengiva ou em rebordo alveolar, sendo a mandíbula mais afetada do que a maxila. Os primeiros estudos apontaram que a LPCG se tratava de uma lesão reparativa devido a uma resposta inflamatória ${ }^{1}$.

A LPCG possui uma grande predominância em região de mucosa gengival e rebordo alveolar edêntulo, apresentando um aumento de volume nodular com coloração vermelha escura; devido à grande vascularização e à sua cor típica, está relacionada ao depósito de hemossiderinas e hematoidina na periferia da lesão. Em razão desses achados, a lesão pode apresentar sangramento à palpação ${ }^{2}$. Pode também se manifestar em qualquer faixa etária, preferencialmente da primeira à sexta década de vida, atingindo, em mais da metade dos casos, pessoas do sexo feminino entre 31 e 41 anos de idade.

Radiograficamente, trata-se de uma lesão radiolúcida com ausência de bordas definidas, podendo apresentar halo radiopaco ao redor da lesão. Uma Patologia Bucal e Pacientes com Necessidades Especiais. 
característica importante radiograficamente é a reabsorção em forma de "taça" do osso alveolar subjacente à lesão. Em relação aos achados histopatológicos, a LPCG mostra a presença de células gigantes, classificando-se como uma hiperplasia de clastos em que as células gigantes formam-se a partir da junção de outras células ${ }^{3}$. Sendo assim, o exame histopatológico é imprescindível para que se realize o diagnóstico definitivo dessa patologia.

O diagnóstico diferencial desse tipo de lesão é o granuloma piogênico, por causa de seu aspecto clínico bastante similar à $\mathrm{LPCG}^{1,2}$ e à Lesão Central de Células Gigantes (LCCG), que apresenta localização intraóssea ${ }^{1,3}$. Atualmente sabe-se que a LCCG é uma lesão mais agressiva do que a LPCG ${ }^{4}$.

O tratamento da LPCG consiste na excisão cirúrgica local, abaixo do osso subjacente. Os fatores irritantes, como excesso de restaurações, próteses mal-adaptadas, exodontias traumáticas, restos alimentares impactados, placa bacteriana e cálculo, devem ser removidos com uma raspagem da tábua óssea da região afetada, para evitar recidivas da lesão².

Portanto, o presente relato de caso é de grande importância, pois a LPCG em região palatina é incomum, e o paciente encontra-se com um tempo de proservação considerável, não mostrando qualquer sinal clínico de recidiva da lesão.

\section{Relato de caso}

Paciente do sexo feminino, melanoderma, 38 anos de idade, compareceu ao Serviço de Estomatologia da Universidade Federal do Ceará (UFC), campus Sobral, no mês de maio de 2016, queixando-se de "inchaço em região anterior do palato duro".

No exame físico intraoral, notou-se um crescimento exofítico em região anterior de palato duro. Vale ressaltar a higiene oral inadequada, com presença de cálculo subgengival e raízes residuais. A lesão apresentava formato nodular, de superfície lobulada, com áreas ulceradas, medindo $20 \mathrm{~mm}$, localizada na região de papila incisiva (Figura 1). Durante palpação, verificou-se aumento de volume de consistência amolecida, porém, sem sintomatologia. Também se constatou afastamento dos dentes $11 \mathrm{e}$ 21, causando diastema.

Frente à lesão, foi recomendada a realização da biópsia excisional, com a hipótese diagnóstica de granuloma piogênico e diagnóstico diferencial de lesão periférica de células gigantes. Sob anestesia local infiltrativa (cloridrato de mepivacaína a $3 \%$ ), foram realizadas a incisão do pedículo, com o cuidado de curetar a região rente ao periósteo, assim como a curetagem radicular dos dentes 11 e 21 , com o intuito de evitar a recorrência da lesão (Figura 2). A lesão foi fixada em formol a $10 \%$ e encaminhada ao Laboratório de Patologia Oral da Universidade Federal do Ceará. No exame histopatológico, observou-se uma proliferação de células gigantes multinucleadas, permeadas por células mesenquimais fusiformes e ovoides, com discreta pigmentação por hemossiderina, corroborando para o diagnóstico de lesão periférica de células gigantes (Figura 3).
A proservação do caso foi realizada durante o ano pós-cirúrgico sem apresentar recidiva. Outro dado importante foi o fechamento do diastema entre os dentes 11 e 21, comprovando que a lesão foi fator causal para a ocorrência de tal afastamento dentário (Figura 4).

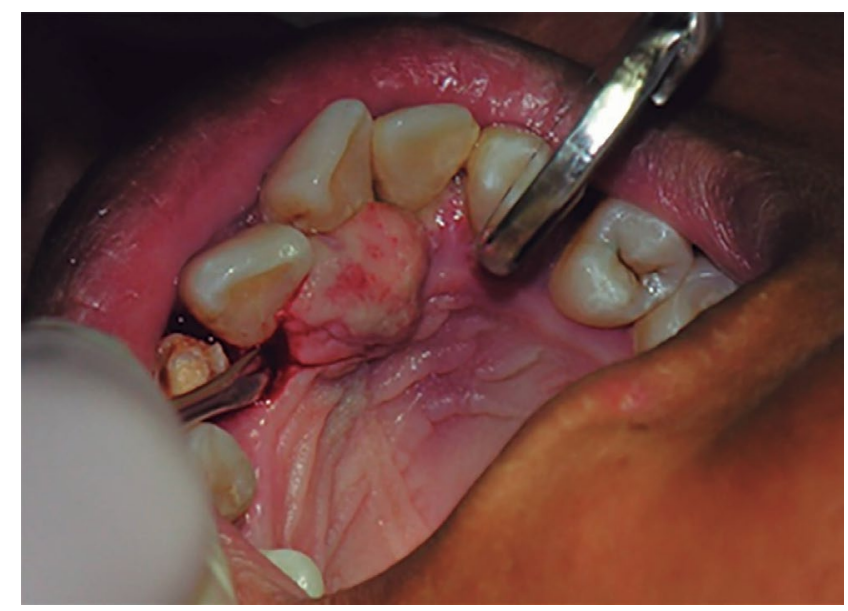

Figura 1 - Lesão em formato nodular, de superfície lobulada, com áreas ulceradas em região de papila incisiva

Fonte: Estomatologia UFC, campus Sobral.

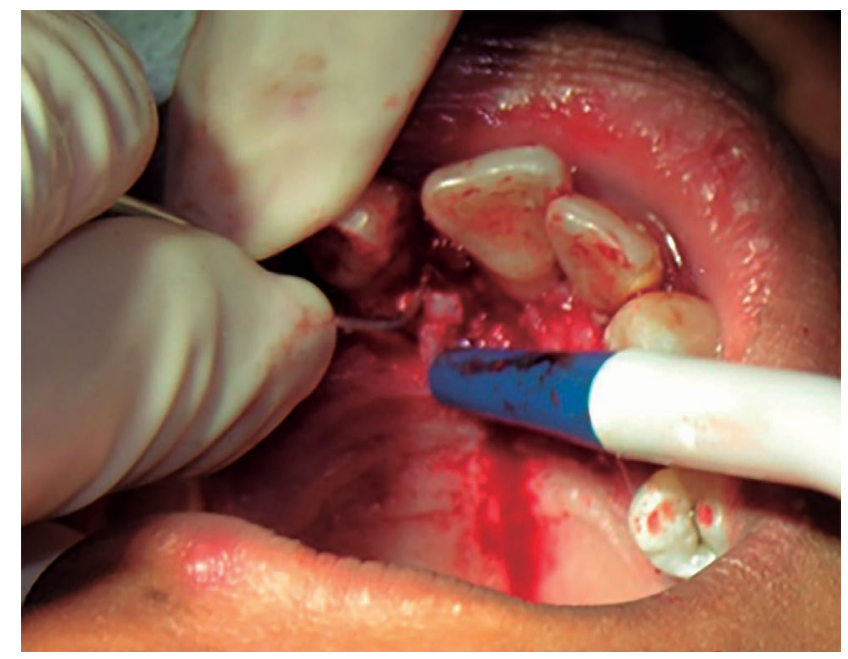

Figura 2 - Curetagem radicular dos dentes 11 e 21. Gengivite hiperêmica

Fonte: Estomatologia UFC, campus Sobral.

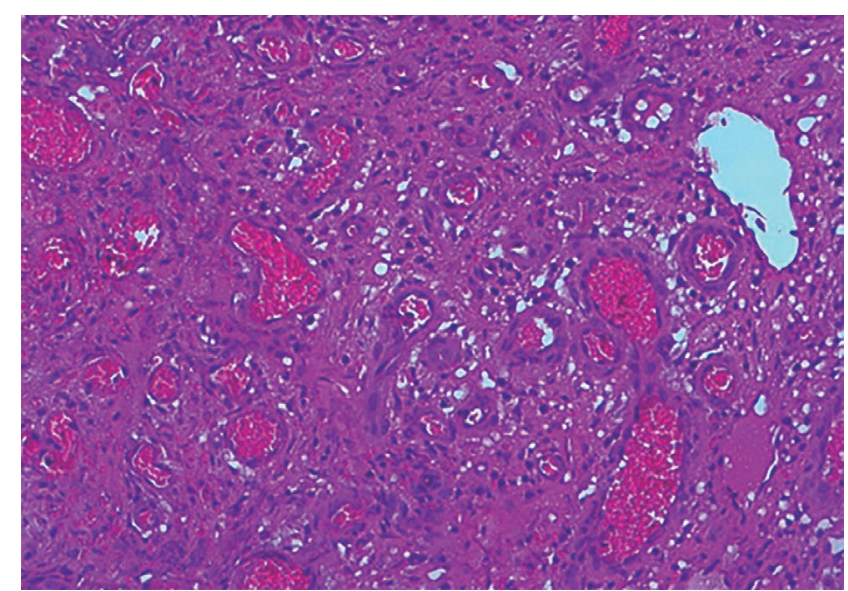

Figura 3 - Fotomicrografia com coloração HE (40x)

Fonte: Estomatologia UFC, campus Sobral. 


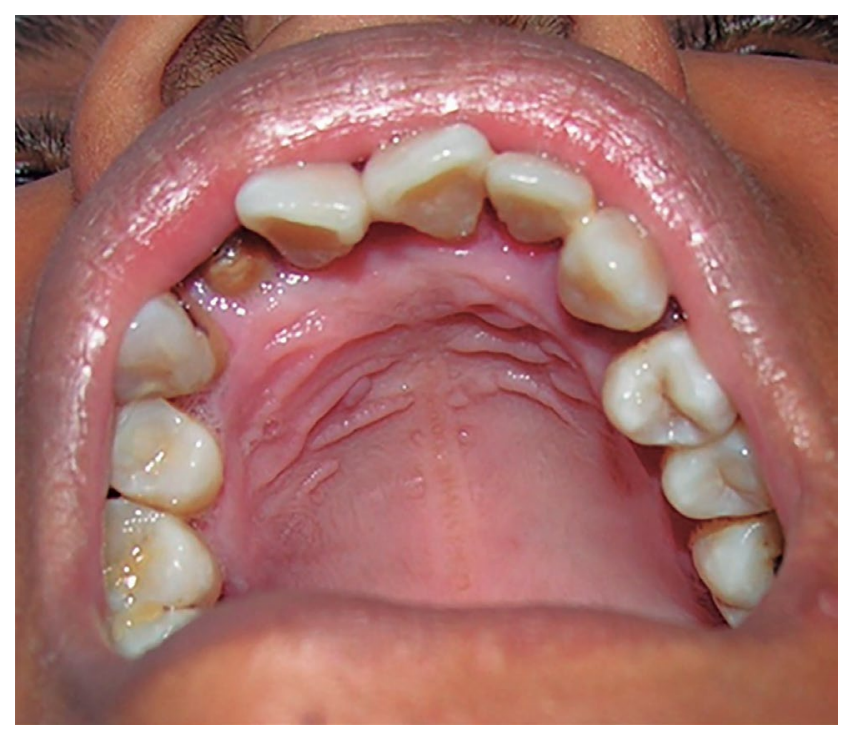

Figura 4 - Pós-operatório de 1 ano

Fonte: Estomatologia UFC, campus Sobral.

\section{Discussão}

A LPCG é uma lesão reacional de etiologia desconhecida, porém, com associação aos fatores traumático e irritativo locais. Exemplos desses fatores são cálculos subgengivais, próteses mal-adaptadas, entre outros. Logo, os fatores traumático e irritativo crônicos devem ser eliminados, a fim de que se possa descartar o quadro recidivante. Ao analisar clinicamente o caso, pode-se notar similaridade com o granuloma piogênico. Uma das formas para diferenciar tais lesões é o exame histopatológico, pois ambas apresentam características histológicas distintas.

Segundo diversos autores, a LPCG é predominante no sexo feminino ${ }^{1,5,6,7}$. Alguns estudos demonstram que a condição sistêmica atrelada ao fator hormonal pode explicar o maior acometimento do sexo feminino ${ }^{8-20}$. Existe um quadro de imunossupressão durante o período gestacional ${ }^{18,12,19}$, com a elevação dos níveis hormonais sexuais femininos, como o estrógeno, o gonadotrofina coriônica e o progesterona ${ }^{21}$. Com isso, desenvolvem-se efeitos sobre as glândulas endócrinas na região da mucosa oral, fazendo com que haja uma elevação na deposição de glicogênio no epitélio gengival, que são produzidos pelos estrógenos, alterações vasculares que serão induzidas pelo hormônio sexual feminino progesterona, resultando, assim, em um quadro de gengivite hiperêmica e hiperplasia papilar; essa cascata de eventos pode contribuir para o desenvolvimento de processos proliferativos nos sítios que apresentam gengivite pré-existente ${ }^{12,21}$. Foi relatado que alguns casos de LPCG poderiam ser influenciados por hormônios sexuais devido aos receptores ${ }^{20}$.

A LPCG tem rápido crescimento durante o período gestacional, evidenciando a possível relação com os hormônios sexuais ${ }^{12}$, sendo que tais hormônios podem influenciar secundariamente ${ }^{8,19}$. Portanto, o presente caso clínico corrobora com o que esses achados da literatura preconizam. Entretanto, vale relatar estudos que discordam quanto à relação ao sexo predominante: 0 estudo de Resende ${ }^{16}$ (2007) afirma que o sexo masculino é o mais acometido, e o de Lester et al. ${ }^{14}(2014)$ conclui que não há predileção por sexo (Tabela 1).

Tabela 1 - Relação da LPCG com sexo, sítio e idade em diferentes países, segundo a literatura estudada

\begin{tabular}{|c|c|c|c|c|c|}
\hline Autor & Ano & Sexo & Sítio & Idade & País \\
\hline Katsikeris et al. ${ }^{15}$ & 1988 & Feminino & Mandíbula & $>40$ anos & Grécia \\
\hline Ferreira e Cavezzi ${ }^{1}$ & 2008 & Feminino & Mandíbula & $>30$ anos & Brasil \\
\hline Resende $^{16}$ & 2007 & Masculino & Maxila & $<18$ anos & Brasil \\
\hline Shadman et al. ${ }^{5}$ & 2009 & Feminino & Mandíbula & $>33$ anos & Irã \\
\hline Lester et al. ${ }^{14}$ & 2014 & Sem predileção & Mandíbula & $>15$ anos & EUA \\
\hline Maturama-Ramírez et al. ${ }^{6}$ & 2015 & Feminino & Maxila & $>50$ anos & Chile \\
\hline
\end{tabular}

Em relação ao sítio de localização, pode-se notar uma prevalência em região de mandíbula ${ }^{1,5,7,8,22}$. Contudo, os estudos de Resende ${ }^{16}(2007)$ e Maturama-Ramírez et al. ${ }^{6}(2015)$ afirmam que tal lesão tem maior acometimento em região de maxila, concordando com o presente caso clínico (Tabela 1).

Quando se trata da faixa etária, podemos analisar maior divergência. O presente caso clínico está de acordo com estudos que relatam que o predomínio da LPCG se dá a partir da terceira década de vida $^{1,5,6,7}$. Essa prevalência pode estar relacionada ao fato de que, nas quatro primeiras décadas de vida, existe uma carga hormonal mais pronuncia$\mathrm{da}^{15,17}$. Contudo, o estudo de Lester et al. ${ }^{14}$ (2014) afirma que essa lesão se manifesta em indivíduos acima de 15 anos; e o de Resende ${ }^{16}$ (2007), em menores de 18 anos (Tabela 1 ).

A LPCG não tem predileção por etnia, acometendo tanto caucasianos quanto negros e asiáticos, sem qualquer prevalência maior entre elas ${ }^{18}$. 
Alguns autores acreditam que o maior número de casos que apresentam crescimento gengival relacionado ao fator reacional se deva também à anatomia particular do tecido gengival. Vale ressaltar que não há na literatura relatos de casos em que a LPCG se manifestou em sítios extragengivais. Sendo assim, existe uma possível relação da anatomia gengival com os fatores irritativos locais peculiares a este sítio ${ }^{19}$, como o cálculo subgengival.

Portanto, sugere-se que a LPCG possa ser oriunda do mucoperiósteo ou do ligamento periodontal, como resposta a esse fator irritativo crônico ao periósteo ${ }^{11}$.

Em relação à higiene oral, segundo Bodner et al. ${ }^{3}$ (1997), tem se mostrado pior em pacientes com LPCG de maior extensão, quando comparados àqueles com lesões de menor extensão. Este estudo pode evidenciar a importância da higiene oral em relação ao desenvolvimento e ao crescimento da LPCG, apresentando o cálculo subgengival como esse fator irritativo local.

No presente estudo, o fator irritativo responsável pelo desenvolvimento da lesão também foi o cálculo subgengival, o que está de acordo com Bodner et al. ${ }^{3}$ (1997). As características comuns observadas na análise histopatológica do caso clínico em questão corroboram com o que alguns trabalhos preconizam $^{22,23}$, nos quais foi observada uma proliferação de células gigantes multinucleadas permeadas por células mesenquimais fusiformes e ovoides com discreta pigmentação por hemossiderina.

No que tange ao aspecto terapêutico, o tratamento de escolha é a exérese cirúrgica da lesão com a eliminação dos fatores traumáticos locais. Sendo assim, torna-se importante o controle do biofilme dentário associado aos procedimentos periodontais, para que haja uma redução do quadro inflamatório, mesmo não sendo um tratamento definitivo, mas adjuvante ${ }^{8,12,24-27}$. A LPCG apresenta uma taxa de recorrência de 5 a $70,6 \%$, cuja variação ocorre justamente devido à persistência de fatores irritativos e traumáticos locais, quando não cessados por completo $^{8,25,27,28}$.

A paciente do caso em questão recebeu em acompanhamento pós-operatório de um ano, não apresentando sinais clínicos de recidiva da lesão.

\section{Considerações finais}

O correto diagnóstico torna-se imprescindível para a obtenção de sucesso no tratamento da LPCG. Sendo assim, o exame anatomopatológico é primordial para a identificação de tal patologia. $\mathrm{O}$ cirurgião-dentista deve ter o domínio das técnicas cirúrgicas executadas, já que se deve ater à remoção de toda a base da lesão, a fim de evitar um possível quadro de recorrência. Outro aspecto importante para obtenção de sucesso no tratamento é a remoção dos fatores irritativos por meio de uma higiene oral satisfatória, propiciando melhor controle do biofilme dentário e possibilitando a saúde gengival e periodontal. O acompanhamento pós-operatório deve ser feito por um longo período, devido à alta taxa de recidiva da LPCG.

\section{Abstract}

Peripheral giant cell lesion (LPCG) is considered as a non-neoplastic proliferative process. It is believed that its etiological factor is associated with the reaction factor such as local trauma or irritation. Such lesion may develop in the anterior region and posterior region of the gingiva or in the alveolar ridge, the mandible being more affected than the maxilla. Objective: this study reports a clinical case of a female patient, 38 years old, who had an exophytic growth in the anterior region of the hard palate. Case report: the exophytic growth was in nodular form, with a lobed surface with ulcerated areas, measuring $20 \mathrm{~mm}$, located in the region of incisive papilla. Based on the clinical characteristics, the treatment performed was excisional biopsy followed by scaling and root planing of the upper teeth. Histopathological examination showed areas of giant cell proliferation and mild hemosiderin pigmentation, confirming the diagnostic hypothesis of LPCG. Final considerations: the postoperative follow-up showed an excellent healing process without relapse after one year of treatment initiation.

Keywords: Biopsy. Dental plaque. Giant cell.

\section{Referências}

1. Ferreira FC, Cavezzi JO. Lesão periférica de células gigantes com ossificação. Rev Gaucha Odontol 1994; 42:337-41.

2. Heisenberg A, Kozolovsky A, Schawartz-Arad D, Mardinger O, Kaplan 1. Peripheral giant cell granuloma associate with dental implants. J Periodontol 2003; 74:1381-4.

3. Bodner L, Peist M, Gatot A, Fliss DM. Growth potential of peripheral giant cell granuloma. Oral Surg Oral Med Oral Pathol Oral Radiol Endod 1997; 83:548-51.

4. Vázquez-Piñero MT, González-Bereijo JM, Niembro E. Granuloma periférico de células gigantes: caso clínico y revisión de la literatura. Rev del ilustre Consejo General de Colegios de Odontólogos y Estomatólogos de España (RCOE) 2002; 7:201-6.

5. Shadman N, Ebrahimi SF, Jafari S, Eslami M. Peripheral giant cell granuloma: a review of 123 cases. Dent Res J (Isfahan) 2009 ; $6: 47-50$.

6. Maturama-Ramírez A, Adorno-Farías D, Montserrat Reyes-Rojas M, Farías-Vergara N, Aitken-Saavedra J. A retrospective analysis of reactive hyperplastic lesions of the oral cavity: study of 1149 cases diagnosed between 2000 and 2011, Chile. Acta Odontol Latinoam 2015; 28(2):103-7.

7. França DCC, André NV, Lessi MAA, Reis G, Aguiar SMHCA. Granuloma Periférico de Células Gigantes: relato de caso. Rev Cir Traumatol Buco-Maxilo-Fac Camaragibe 2010; 10(3):29-32.

8. Whitaker SB, Bouquot JE, Alimario AE, Whitaker TJ Jr. Identification and semiquantification of estrogen and progesterone receptors in peripheral giant cell lesions of the jaws. J Periodontol 1994; 65(3):280-3. 
9. Carvalho YR, Loyola AM, Gomez RS, Araújo VC. Peripheral giant cell granuloma. An immunohistochemical and ultrastructural study. Oral Dis 1995; 1(1):20-5.

10. Günhan M, Günhan Ö, Celasun B, Mutlu M, Bostanci H. Estrogen and progesterone receptors in the peripheral giant cell granulomas of the oral cavity. J Oral Sci 1998; 40(2): $57-60$

11. Chambers CB. Massive peripheral giant-cell reparative granuloma of the jaw: a pregnancy dependent tumor (Discussion). Am J Obstet Gynecol 1978; 131(2):178-9.

12. Caillouette JC, Mattar N. Massive peripheral giantcell reparative granuloma of the jaw: a pregnancy dependent tumor. Am J Obstet Gynecol 1978; 131(2):176-9.

13. Daley TD, Nartey N O, Wysocki GP. Pregnancy tumor: an analysis. Oral Surg Oral Med Oral Pathol 1991; 72(2):196-9.

14. Lester SR, Cordell KG, Rosebuch MS, Palailogou AA, Maney P. Peripheral giant cell granulomas: a series of 279 cases. Oral Surg Oral Med Oral Pathol and Oral Radiol 2014; 118(4):475-82.

15. Katsikeris N, Angelopoulos E, Angelopoulos AP. Peripheral giant cell granuloma: clinicopathological study of 224 new cases and review of 956 reported cases. Int J Oral and Maxillofac Surg 1988; 17(2):94-9.

16. Resende CRS. Granuloma periférico de células gigantes: imunohistoquímica Anti-TNF-a [Dissertação de Mestrado]. Duque de Caxias (RJ): Universidade do Grande Rio Prof. José de Souza Herdy; 2007.

17. Eronat N, Aktug M, Giimbay T, Unal T. Peripheral giant cell granuloma: three case reports. J Clin Pediatr Dent 2000; 24(3):245-8

18. Mighell AJ, Robinson PA, Hume WJ. Peripheral giant cell granuloma: a clinical study of 77 cases from 62 patients and literature review. Oral Dis 1995; 1(1):12-9.

19. Brown LJ, Brunelle JA, Kingman A. Periodontal status in United States, 1988-1991: prevalence, extent and demographic variation. J Dent Res 1996; 75:672-83.

20. Shafer WG, Hine MK, Levy BM. A textbook of oral pathology. Philadelphia: WB Saunders; 1983.

21. Neville BW, Damm DD, Allen CM, Bouquot JE. Patologia Oral e Maxilofacial. 3. ed. Rio de Janeiro: Elsevier; 2009. 972p.

22. Marinho TFC, Santos PPA, Albuquerque ACL. Processos proliferativos não-neoplásicos: uma revisão da literatura. Rev Saúde \& Cienc online, 2016; 5(2):94-110.

23. Petris GP, Bremm LL, Tanaka F, Melhado RM, Miura CS. Lesão Periférica de Células Gigantes - Diagnóstico Diferencial e Tratamento da Lesão: Relato de Caso Clínico. Rev Port destomat, Medicina Dentária e Cirurgia Maxilofacial 2008; 49(4):237-40

24. Binnie WH. Periodontal cysts and epulides. Periodontol 2000; 21:16-32.

25. Flaitz C. Peripheral giant cell granuloma: a potentially aggressive lesion in children. Pediatr Dent 2000; 22(3):232-3.

26. Giusto TJ, Baer PN. A peripheral giant cell granuloma mimicking a combined endodontic-periodontic lesion. Periodontal Clin Invest 1996; 18(2):17-9.

27. Mighell AJ, Robinson PA, Hume WJ. Peripheral giant cell granuloma: a clinical study of 77 cases from 62 patients, and literature review. Oral Dis 1995; 1:12-9.

28. Pandolfi PJ, Felefli, Flaitz CM, Johnson JV. An aggressive peripheral giant cell granuloma in a child. J Clin Pediatr Dent 1999; 23(4):353-5.

\section{Endereço para correspondência:}

Samuel Rocha França

Rua Afonso Magalhães, 333, Derby-Sobral CEP: 62042-210, Ceará, Fortaleza, Brasil

Telefone: (88) 9 9999-0026

E-mail: samuelfranca@outlook.com

Recebido: 29/10/17. Aceito: 19/12/17. 